GRASAS Y ACEITES, 57 (1), ENERO-MARZO, 116-125, 2006 ISSN: 0017-3495

\title{
Refining by-products as a source of compounds of high-added value
}

\author{
By Paolo Bondioli
}

Stazione Sperimentale Oli e Grassi, Technology Department, Via Giuseppe Colombo, 79. 20133 MILANO (Italy)

Tel. +39027064 971, Fax. +39022363 953,

e-mail: bondioli@ssog.it, website: www.ssog.it

\section{RESUMEN}

Obtención de compuestos de alto valor añadido a oliva

El trabajo hace una revisión completa de los subproductos obtenidos de la refinación del aceite de oliva Se comentan tanto los subproductos procedentes de la refinación química como de la física. Ioualmente, se comparan los aspectos teccomo de la física. Igualmente, se comparan los aspectos tecnológicos de la valorización de estos subproductos con respecto a los procedentes de otros aceites o grasas. Los unicos subproductos procedentes del aceite de oliva que tienen composición especifica son

PALABRAS-CLAVE: Aceite de oliva - Escualeno Refinación - Subproducto.

\section{SUMMARY}

Refining by-products as a source of compounds of high-added value

In this paper a complete review of by-products coming from the olive oil refining process is reported. By-products from both chemical and physical refining are discussed, along with their compositional properties. Also the technological aspects of by-product valorisation are discussed in comparison with the competitors coming from other oils and fats. The only olive oil by-products having unique composition are the ones containing squalene in high concentration. Squalene.

KEY-WORDS: By-product - Olive oil - Refining -

\section{INTRODUCTION}

The annual production of olive oil, mainly concentrated in the Mediterranean area but with interesting and recent developments in North America and Far East, actually accounts (production 2003-2004) at approximately 3.000.000 ton/year, of which approximately the $80 \%$ is produced in EU Countries (mainly Spain and Italy) (Anonymous, 2004).

According to the seasonal behaviour and to the chemical and sensorial properties the ratio between the oil that can be directly consumed (extra virgin/virgin oil) and the oil to be sent at refining process (lampante oil) changes in a very wide range.
There are numerous vegetable oil refineries processing lampante olive oil for the production of refined olive oil that, before being marketed, will be blended with virgin oil to achieve the minimum requirements necessary for its classification as olive oil, according to the European rules (CEE regulation, 1991). The technology used for the refining of non edible lampante olive oils is the same in use world-wide for the refining of all vegetable or tropical oils.

It is not within the scope of this paper to discuss in detail these technologies, but a short overview is necessary, in order to understand where the stream of different by products comes from and which could be the problems related to a specific production step.

Two different refining technologies are actually in use for the refining of vegetable oils, the chemical and the physical process. A synthetic description of chemical refining is shown in Figure 1.

After a pre-treatment with a reduced amount of diluted acid such as phosphoric acid, citric acid etc., the acidic oil is treated with a $10-20 \% \mathrm{NaOH}$ aqueous solution (in quantity sufficient to neutralise the existing free fatty acid content, the mineral acid added, increased of a slight excess for a complete acidity removal and to ensure a suitable fluidity of obtained soaps). At the end of neutralisation step the soaps are removed by settling or centrifugation and the resulting neutralised oil is washed with water to remove the last traces of alkali. After wate removal by means of vacuum drying the oil is bleached by contact with activated bleaching earth $(A B E)$. The bleaching process is carried out batchwise or continuously at $60-90{ }^{\circ} \mathrm{C}$, under reduced pressure (50-200 mbar). At the end of the contact period the exhausted bleaching earth (EBE) is removed by filtration. The bleached oil is finally sent to the deodorization section, where the oil is treated with direct steam at high temperature (180$240^{\circ} \mathrm{C}$ ) and in high vacuum conditions (1-2 mbar of residual pressure). After the deodorization step a final cooling treatment is necessary before transferring the refined oil to the storage section. During the chemical refining process three byproducts are generated:

- the soap fraction, obtained after the neutralisation treatment, that is transferred to 


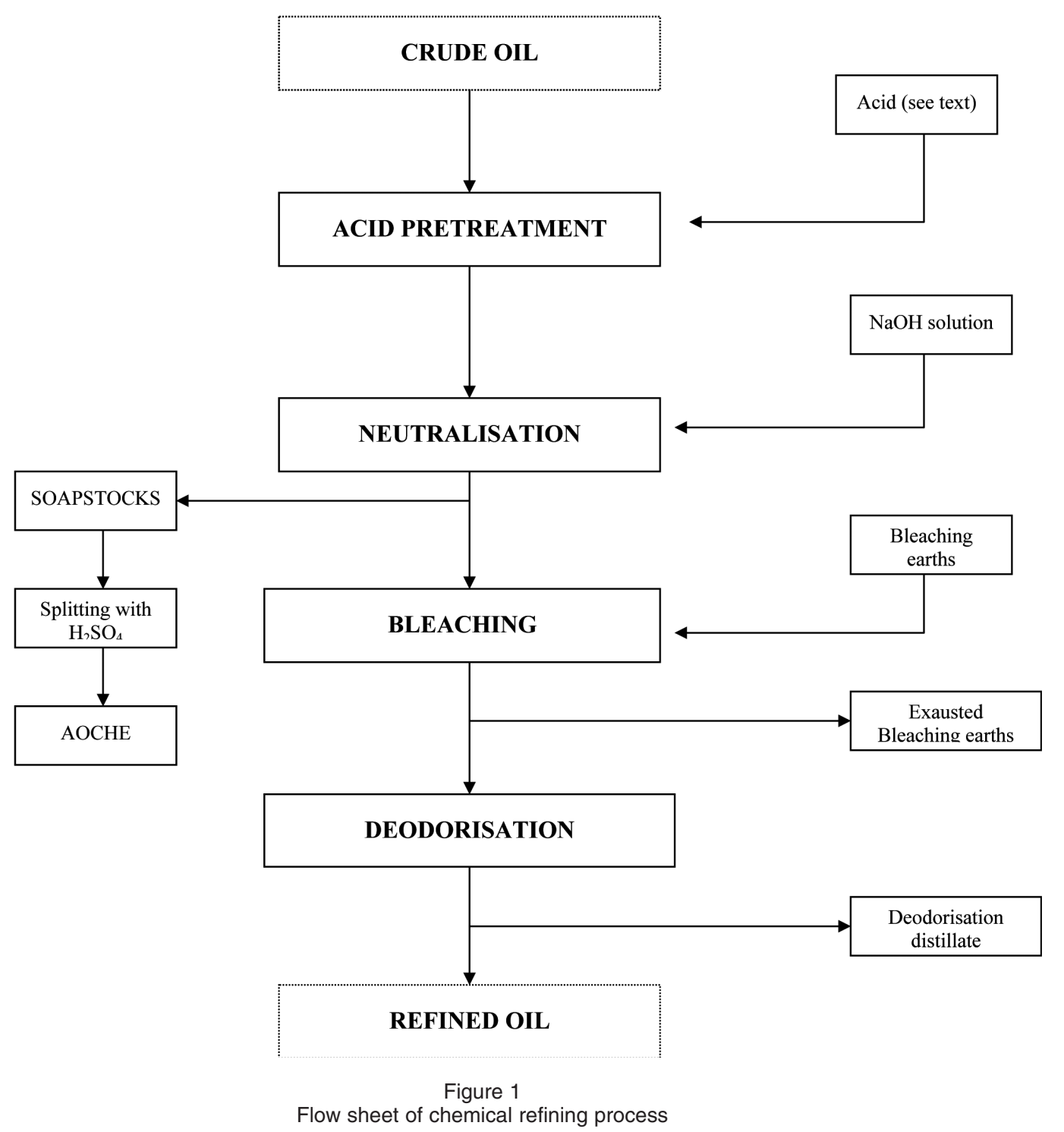

a splitting section where, after treatment with mineral acid the fatty mixture constituted of free fatty acids, oil and impurities (generally recognised as acid oil from chemical refining $\mathrm{AOCHE}$ ) is recovered from the oil/water emulsion;

- the EBE, containing approximately 30-50 \% in weight of oil, as a function of the efficiency of filtering units and of the steam/air blowing device for oil recovery;

- the deodorization distillate, recovered inside the deodorization unit, where a scrubber is present for the washing of vapours coming from the processing of the oil.

The physical refining process, on the contrary, allows the removal of free fatty acids by means of distillation, carried out at high temperature, high vacuum and using a direct steam injection. There are several similarities between deodorization (for chemical process) and neutralisation (for physical process), but this last is carried out under more drastic processing conditions and leads to the separation of a greater amount of by-product. A flow sheet of a physical refining process is reported in Figure 2, where several operating steps can be identified:

- a pre-treatment with diluted mineral acids for the removal of impurities, having the same characteristics of the one previously described for chemical refining. In this case the stream very reduced in terms of mass impact is separated and immediately delivered to the waste water treatment unit;

- a bleaching step, carried out in the same conditions described above for chemical refining, leading to the separation of EBE;

- a physical neutralisation step, where free fatty acids are removed by steam distillation. During this step also deodorization of oil takes place and the resulting oil, after the final cooling, represents the refined product.

During the physical refining process two byproducts are generated: 
- the EBE, containing approximately $30-50 \%$ in weight of oil, as a function of the efficiency of filtering units and of the steam/air blowing device for oil recovery;

- the acid oil from physical refining, recovered inside the distillation unit and consisting of free fatty acids, components of the unsaponifiable fraction, odorous compounds, etc.

In Table 1 a review of all mentioned by-products is reported along with a rough evaluation of the produced amount and of the qualitative composition.

\section{ACID OILS FROM CHEMICAL REFINING} (AOCHE)

The AOCHE by-product is practically represented by a mixture of free fatty acids and neutral oil, with some minor components in reduced amount. The relative ratio between FFA and oil depends on the efficiency and on the technology used for oil refining as well as on the initial FFA content of crude oil. It is well known from the literature (Martinenghi, 1971) that the neutralisation coefficient for chemical refining (expressed as the ratio between the \% weight loss during neutralisation and the initial FFA content) is a function of the free fatty acid content of crude oil, and may vary from 1,5 for low acidity values up $2-3$ for higher values. It is generally recognised that oils having a FFA content higher than 7-10 (as oleic acid $\%$ ) cannot be processed chemically because of the very high neutralisation losses. In this case the only solution is using the physical refining process.

Owing to their composition AOCHEs cannot be used as they are, but must be previously transformed in a more standardised product. From our experience AOCHEs have an Acid Value ranging between 100 to 140 , and a Saponification Value around 185-195. Both values are expressed as $\mathrm{mg}$ $\mathrm{KOH} / \mathrm{g}$. The difference existing between SV and AV represents the amount of esters in the sample (mainly triglycerides, representing the oil losses during neutralisation). As stated before it is necessary to obtain, from this mixture, a standardised product. This objective can be achieved by splitting the remaining triglycerides with water under pressure to obtain a mixture of different fatty acids. The reduced quantity of glycerol produced during the splitting step is separated with water into the splitting tower. The crude mixture of different fatty acids, having the same composition of olive oil must be afterwards purified by vacuum distillation, in order to remove the unsaponifiable fraction and the colour. During this unit operation it is also possible to remove, by "cutting the head of distillate", the main part of palmitic acid that, because of its high melting point, reduces the spectra of possible applications for these fatty acids.

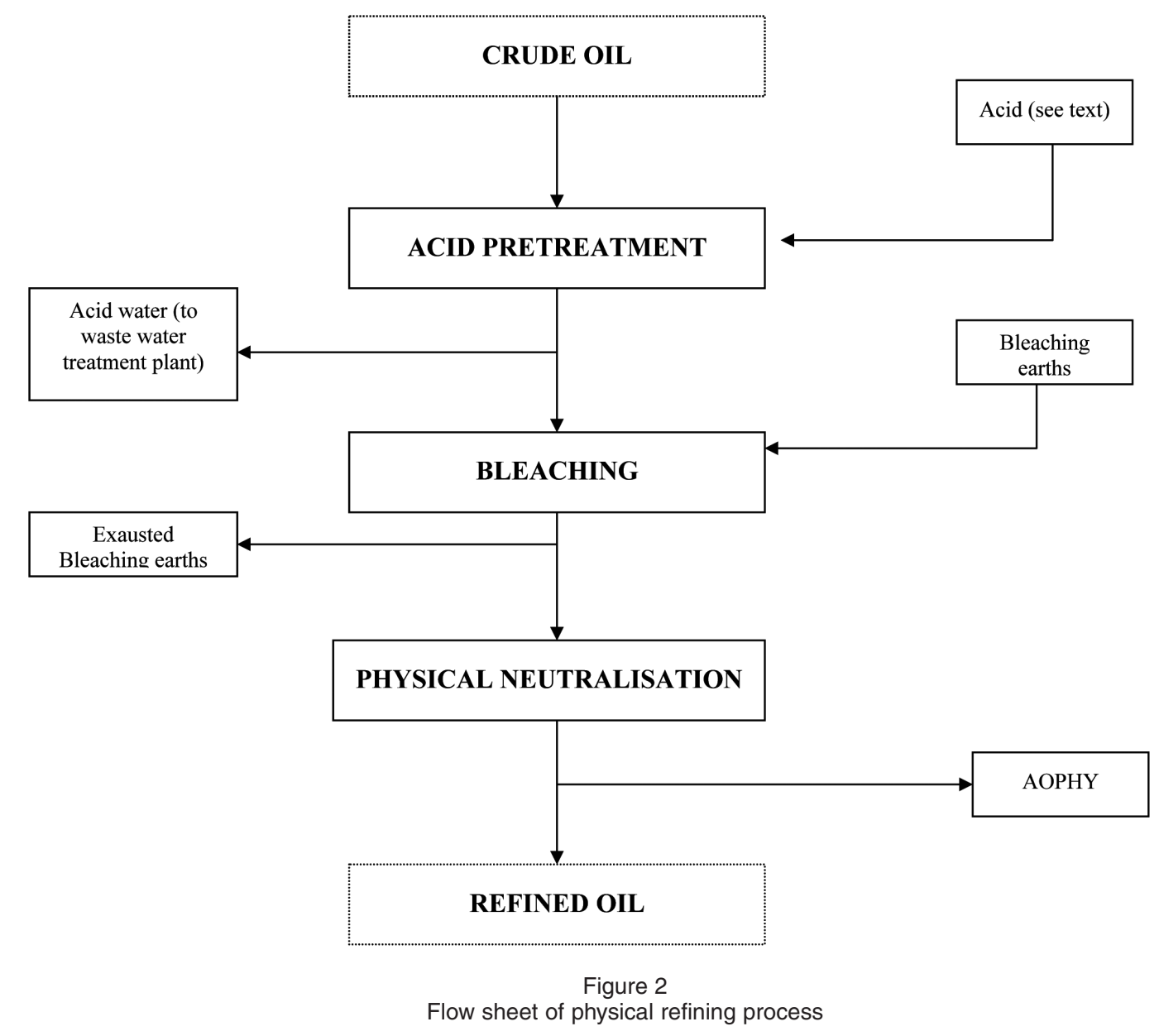


Table 1

Main by products generated from olive oil refining

\begin{tabular}{|c|c|c|c|c|}
\hline By-product & Acronym & Process & Main constituents & $\begin{array}{c}\text { Indicative amount } \\
\text { (as \% of } \\
\text { processed oil) }\end{array}$ \\
\hline $\begin{array}{l}\text { Acid oils from } \\
\text { chemical refining }\end{array}$ & AOCHE & Chemical & $\begin{array}{l}\text { Free fatty acids, triglycerides, } \\
\text { impurities, moisture }\end{array}$ & 1.6 to $2.0 \times$ FFA \\
\hline $\begin{array}{l}\text { Acid oils from } \\
\text { physical refining }\end{array}$ & AOPHY & Physical & $\begin{array}{l}\text { Free fatty acids, unsaponifiable, } \\
\text { squalene, volatile compounds }\end{array}$ & 1.1 to $1.4 \times$ FFA \\
\hline $\begin{array}{l}\text { Exhausted Bleaching } \\
\text { Earths }\end{array}$ & EBE & $\begin{array}{l}\text { Chemical } \\
\text { and Physical }\end{array}$ & $\begin{array}{l}\text { Bleaching earth, oil, } \\
\text { oxidation products, pigments }\end{array}$ & 0.5 to 2.0 \\
\hline Deodorisation distillate & OODD & Chemical & $\begin{array}{l}\text { Monoesters, unsaponifiable, } \\
\text { free fatty acids, volatile compounds }\end{array}$ & 0.1 to 0.2 \\
\hline
\end{tabular}

The main part of distilled olive oil fatty acids is used for toilet soap preparations (palmitic acid included) and it is generally recognised that soaps prepared from olive oil fatty acids, sometimes in blend with palm oil fatty acids, are of the best available quality. Olive oil fatty acids can be used for a wide variety of application other than soaps, but they are always competitors of fatty acids coming from other different vegetable or animal oils. The oleochemical industry during the time has developed a number of different technologies, generally based on distillation and cold fractionation, allowing the preparation of selected mixtures of fatty acids from different feedstock. This fact makes the factor "selling price" the most critical and olive oil fatty acids can be used by oleochemical industry if price is convenient, otherwise other alternative materials will be processed.

It is easy to predict that the main interest for olive oil fatty acids is based on their high content in oleic acid, allowing the preparation of different esters for technical applications with interesting properties in viscosity, resistance to the oxidation and good cold behaviour (Bondioli, 2001). From time to time all oleic esters were prepared from oils of animal origin coming from the cold fractionation of beef tallow fatty acids, ensuring reduced cost and good performances. But during these last years several new facts appeared of fatty acids market:

- the BSE disease, with a strong impact on bovine derived products, made the consumer suspicious towards products coming from cow. We must remark that in the case of distilled tallow fatty acids this is a complete non-sense, if we look at the temperature/time/pressure operating conditions in use during splitting and distillation;

- the increased consumer sensitivity towards the animal welfare, pushing up the request for cosmetics, foods, etc., of sure vegetable origin;

- the increased circulation of goods, related to the globalisation effect, that made request for Kosher and Halal products economically interesting also for companies not directly involved in these markets. A very interesting paper on this subject was recently published by Riaz and Chaundry (2004) and it underlines the growing interest for these products, mainly of vegetable origin for food, feed, cosmetic applications. Another less known aspect of this phenomenon is related to the request for Kosher or Halal products also for auxiliaries, that is to say, for all products in use for food processing, such as the lubrication of producing plants, the lubricants in use for processing of aluminium coil for food packaging, etc.(Bondioli and Sala, 2005).

All these listed factors make us more optimistic about the future of refining by products of vegetable origin: in the near future probably for numerous applications these fatty materials will become more and more attractive. Notwithstanding this perspective, the starting statement about the technical possibility of using different feedstock for the preparation of derivatives still remains and the selling price of AOCHE will be determinant for marketing.

Another interesting perspective for the use of AOCHEs from olive oil comes from the feed formulation market. The use of acid oils in animal nutrition is achieving a growing interest, thanks to good prices and nutrition performances. In this case also the competition with other fatty by products having comparable composition still exist, but products from olive oil probably have a different appeal in terms of flavour and desirability. From olive oil acid oils also a number of interesting derivatives can be prepared to add value and nutritional significance at the products. In particular we must remember:

- the production of fatty acid calcium soaps, insoluble in rumen but readily available in abomasus of ruminants, are used as by-pass fats, when the need to avoid bacterial degradation and isomerisation of fatty materia in rumen is a key point (Bondioli et al., 1993a);

- the production of mono- and diglycerides of fatty acids by superglycerination of AOCHEs, for the preparation of fats devoted to the nutrition of broilers having special nutrition requirements. 
The growing market for these products for feeding purposes created an interest and a need for rules and standard procedures for classification, control and trade. For this reason the European Community is actually supporting within the $6^{\text {th }} \mathrm{FP}$ the "Feeding Fats Safety" research project having these three items within its scopes. A dedicated website is available to know more about this project (www.ub.edu/feedfat).

Oleic acid from olive oil by-products can also represent an interesting starting material for Emery process, where double bonds are cleaved by means of ozone, in order to produce a dicarboxylic acid (azelaic acid, $\mathrm{C}_{9} \mathrm{H}_{22} \mathrm{O}_{4}$ ) and a short chain fatty acid (pelargonic acid, $\mathrm{C}_{9} \mathrm{H}_{18} \mathrm{O}_{2}$ ). The fatty acids from olive oil are useful for this scope thanks to their high oleic acid concentration and to the contemporary practical absence of linolenic acid that during the ozonolysis reaction generates four low molecular weight fragments that must be separated to fulfil the azelaic acid purity requirements.

Finally it is also possible to prepare biodiesel, intended as the alternative renewable fuel for diesel engines constituted of fatty acid methyl esters, from olive oil fatty acids by direct esterification with methanol. Some papers about this subject (Agarwal and Das, 2001; Kalligeros et al., 2003) underline the good fuel properties of the obtained product, with the only limitation of cold properties (Cloud Point $-2^{\circ} \mathrm{C}$, Pour Point $-3^{\circ} \mathrm{C}$ ), that are naturally reduced because of the presence of $10-12 \%$ of high melting palmitic acid methyl ester in this mixture.

Just for completeness of information we must remind a new process, recently patented and published by two American researchers (Lavas, 2003), allowing the preparation of biodiesel from soapstocks obtained from chemical refining of oils, and hence applicable also at olive oil soapstocks. In few words the process consists of an alkali treatment, carried out in order to complete the saponification of the neutral fraction of soapstock, followed by an acidic treatment to split the soaps to obtain fatty acids and a final direct esterification with methanol in presence of an acidic catalyst.

\section{ACID OILS FROM PHYSICAL REFINING (AOPHY)}

This by-product, obtained by vacuum/steam distillation of acidic oils shows several differences from the corresponding one chemically obtained.
The simple evaluation of SV (in our experience ranging between 150 and $190 \mathrm{mg} \mathrm{KOH} / \mathrm{g}$ ) and of acid value (range 110-180 $\mathrm{mg} \mathrm{KOH} / \mathrm{g}$ ) does not provide useful informations. Obviously, being the neutralisation coefficient more favourable in this case the AV values will be higher than the corresponding values for AOCHEs. Also in general the SV/AV ratio is lower for AOPHYs, confirming what expected if we consider that in this case the losses due to trygliceride dragging can be regarded as negligible. But, while in all samples of acid oils coming from chemical refining the SV fits with theoretical value for a mixture oleic acid/olive oil, for AOPHY this SV is frequently lower, but not the same as AV. This fact can be explained by considering two different reasons concurring to achieve this result:

- the existing difference between AV and SV is only partly justified by the presence of mono-, di- and triglycerides, because an important contribution to the final value comes from the natural presence of methyl- and ethylesters of fatty acids. The presence of these esters is well known and described in the literature (Fedeli and Jacini, 1971). We shall approach in detail this fact later, when discussing abou the deodorization distillates, where the monoesters are more concentrated;

- the presence in AOPHYs of important amoun of unsaponifiable material, concurring to lower either AV or SV. We must remembe that the main mass fraction of olive oil unsaponifiable is represented by squalene $(2,6,10,15,19,23$-hexamethyl 2,6,10,14,18, 20 -tetracosaene, Figure 3 ) that is readily volatile under the processing conditions in use during the physical neutralisation.

Obviously the impact of the presence of these two classes of compounds on AOPHYs strictly depends on the FFA content of the crude oil. If we consider as nearly constant the concentration of both squalene and monoesters in crude olive oil, we can evaluate that their final concentration in the distillate will depend on the amount of distilled free fatty acids removed from crude oil to get a neutralised one.

The Figure 4 shows a comparison of GLC path obtained from the two products, after methylation of free carboxylic groups by diazomethane and derivatisation of alcoholic moieties with sylilating reagent.

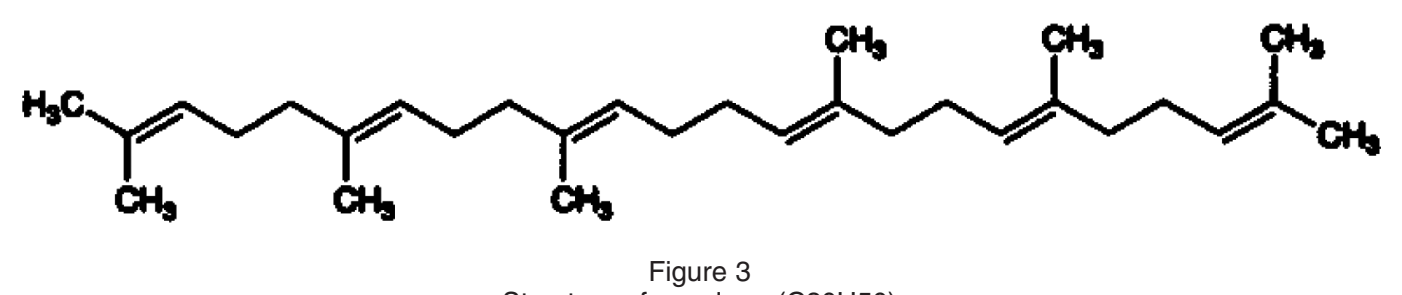

Figure 3
Structure of squalene $(\mathrm{C} 30 \mathrm{H} 50)$ 

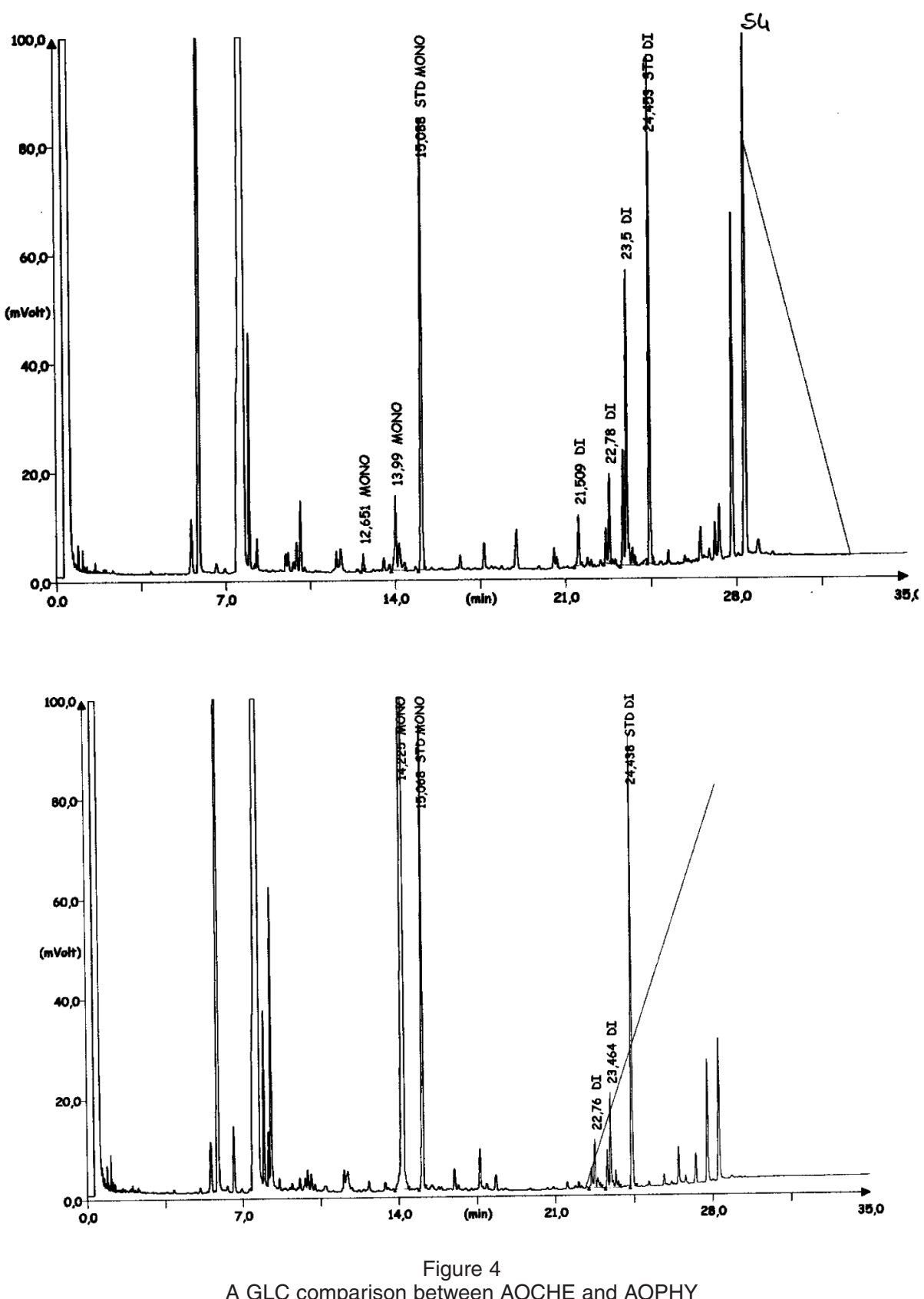

The analysis was carried out in the temperature range between 80 and $350{ }^{\circ} \mathrm{C}$, using a non polar capillary column and a cold on-column injector. Looking at the two paths one can observe that the concentration of triglycerides (RT around $28 \mathrm{~min}$.) is elevated in AOCHE but reduced in AOPHY and the same can be said for partial glycerides such as diglycerides $(\mathrm{RT} \approx 21-24 \mathrm{~min})$ and for monoglycerides ( $R T \approx 12-14 \mathrm{~min}$ ), while fatty acids (as methyl esters) and native methyl and ethyl esters are eluted at a RT $\approx 5-8 \mathrm{~min}$.

The peaks having $\mathrm{RT}=15,1 \mathrm{~min}$. and $R T=24,4$ min. are internal standards used for the quantification of mono- and diglycerides, respectively. It is interesting to remark in this AOPHY sample the important concentration of squalene $(R T=14,2)$ confirming what previously stated.

When discussing about the possible uses of this by-product we must repeat more or less the same concepts reported before:

- this feedstock cannot be used as it is, but it must be pre-treated, in order to remove all esters by means of hydrolisis. In this case particular care might be paid because of the presence of fatty acids methyl and ethyl esters, that are more resistant at the hydrolitic attack than the corresponding triglycerides;

- after splitting the fatty acids must be distilled, in order to remove the unsaponifiable fraction. 
About the uses of these fatty acids nothing different than the uses previously reported for AOCHEs can be said, but some reflections could be done about the possible recovery of the olive oil unsaponifiable fraction after the distillation of free fatty acids.

The use of olive oil unsaponifiable is widely diffused in cosmetic and soap industry thanks to the useful and positive properties of this mixture. Obviously, if we need to recover this fraction, we must protect it during processing, by avoiding over heating periods, oxidation processes and metal contamination. These three aspects can be minimised by following correct technological procedures and with an accurate choice of equipment for processing. In this case in particular the short path distillation technique might be preferred in order to remove free fatty acids from the unsaponifiable fraction with the minimum impact in terms of thermal degradation and darkening of products that, we must remind once again, are obtained as a bottom product from vacuum or short path distillation.

Also the economic recovery of squalene from AOPHY can be considered. This item will be discussed later with deodorization distillates.

\section{EXHAUSTED BLEACHING EARTH (EBE)}

This solid by-product is generated during the bleaching of olive oil both from chemical and physical process. This material contains $20-50 \%$ of oil, depending on technological decision and on the efficiency of the utilised equipment.

Nowadays the oil here contained is regarded as non suitable for food and feed applications, for a number of different reasons, ranging from the concentration of oxidised products, to the possible presence of environmental contaminants, etc.

This fact must be clear in mind when evaluating the economical feasibility to recover this oil: the reference price for this product is not the price of crude olive oil, but the price of an used oil for industrial purposes. On the other hand the EBE represents an environmental problem, generally solved by disposing off these residues in dumps. But also in this case two problems still remain:

- the strong odour of this residue, that worsen day by day, because of the oil oxidation process;

- the same oxidation process of the oil distributed in a very high specific surface in contact with air, might represent a strong fire hazard, so that the EBE storage and disposal must be organised in a way to avoid this risk.

During the time several initiatives were put in operation in olive oil refineries to reduce the impact of EBE on process economy and on the fire and environmental risk:
- the reduction of the quantity of bleaching agent in use during refining: this goal was achieved by improving the quality of crude oils and of purification process. Oils submitted to top degumming (superdegumming) require less bleaching agent than the same oil treated in classical way. Also improving the efficiency of water washing step after the chemical neutralisation, leading to a lower content of residual soaps in neutralised oil, has a strong impact on the required amount of bleaching earth. In addition, during the early '90 appeared on the market a special synthetic silica agent that, notwithstanding its bleaching power close to zero, allowed to remove all trace materials having negative impact on bleaching (soaps, phospholipids, metals), with the contemporary possibility to greatly reduce the amount of $A B E$ to be used. The final result was a reduced amount of solid waste generated, with benefits concerning the reduction of oil losses during bleaching and the reduction of costs for disposal (Bondioli et al., 1989; Bondioli et al. 1990);

- the recovery of the oil contained in EBE: once verified the economical suitability it represents a feasible technology that can be carried out using solvents (hexane is generally preferred), hot water or sodium carbonate aqueous solutions. In every case the recovered oil, dark and highly oxidised, must be used for technical purposes only. An interesting and comprehensive review of these procedures and of the related problems is reported in a monograph on bleaching published by the American Oil Chemists' Society (Patterson, 1992). In our Institute 20 years ago several test were carried out for the recovery of oil from EBE by coupling an hot water and a centrifugation treatment. The obtained results were encouraging but they did not stimulate the interest of refining industries, probably because of the low value of the recovered oil and of the amount of water to be treated at the end of process.

The actual destinations of EBE coming from the refining process are, in our knowledge, three: i) direct disposal in dumps, ii) use as energetic product in oven for the production of concrete, iii) solvent recovery of oil in factories specially equipped and authorised for the processing of used vegetable and animal oils.

\section{OLIVE OIL DEODORIZATION DISTILLATES (OODD)}

This by-product is surely the most interesting under the scientific standpoint and several papers have been published on this subject. Under the economical aspect it should be valorised in a very good way, but the produced amounts are very reduced (we can estimate the $0.1-0.2 \%$ of the olive 
oil mass refined by chemical process) and are regarded as a meaningless product by refiners. In general, because of the low amount produced the OODDs are pooled with AOCHEs (sometimes creating problems). The gross chemical composition of several samples of OODD as determined in our laboratory is shown in Table 2.

For the complete routine evaluation of this feedstock only three determinations are necessary: i) squalene content, generally carried out using one of the available GC or HPLC methods, ii) the Acid of the available GC or HPLC methods, ii) the Acid
Value, allowing to evaluate the presence of free fatty acids, as oleic acid and iii) the Saponification Value, used as described before in case of $\mathrm{AOCHE}$ and allowing to evaluate the amount of fatty acid monoesters, as methyloleate. Obviously a number of other minor components in low concentration can be found in OODD: hydrocarbons other than squalene, sterols, alcohols, tochopherols, numerous products coming from neoformation or thermal cracking of natural molecules.

The main commercial interest for OODD comes from the high content in unsaponifiable fraction, with special reference to the above mentioned unsaturated hydrocarbon squalene. Squalene and its hydrogenation derivative Squalane are classically obtained from shark liver oil (The Merck Index, 1996). Since 1980 there is a request for squalene/squalane of alternative/vegetable origin because of several reasons, ranging from ethical issues towards the animal wildlife respect till contamination problems, since the oil of big fishes is frequently contaminated with POPs, such as dioxines, PCBs, PBDEs, etc.

The alternative squalene sources from vegetables are actually the OODD, the AOPHY and the oil extracted from Amaranth seed (Sun et al., 1997; Sala et al., 1998). Also in numerous vegetable oils and fats the presence of Squalene was detected in limited amounts (Gapor et al., 1985). Squalene is an intermediate of cholesterol biosynthesis and it is generally used as a carrier for active lipophilic molecules, thanks to its high capacity the overpass the skin barrier, as an intermediate of pharmaceutical products. Also dietetic/ethnic applications are recorded in the Far East, but the main world consumption is reported for cosmetic uses. During these last years the commercial demand for Squalene diminished, because of the uncertainty of supply that forced the interested industries to look for more suitable alternatives.

The recovery of Squalene both from OODDs and AOPHYs is a fascinating challenge that occupied researchers during the last 30 years. The first paper on this subject was published by Serra Mastlé and Martinez Moreno (1981), who critically evaluated the squalene enrichment by thiourea complexation, by unsaponifiable fractionation and by vacuum fractional distillation using $A O P H Y$ as a starting material. Some years later an English patent application (Casanova, 1989) claimed the possibility to purify squalene from the completely saponified AOPHY by steam distillation under vacuum. More recently, Bondioli et al. (1993b), demonstrated the feasibility of Squalene purification by means of a supercritical $\mathrm{CO}_{2}$ separation, carried out in a liquid/liquid countercurrent column, after complete saponification followed by esterification with glycerol of the starting material. Before paper a patent application was presented (Bondioli et al., 1992) and few years later a project for furthe development was presented and financed by EC under the name of "New process for the generation of squalene/squalane with supercritical fluid extraction from waste of olive oil production and hydrogenation to squalane" (FAIR2-CT95-1075) This project was evaluated as very successful, because two alternative techniques for the recovery and purification of squalene from OODD were set up by $\mathrm{CO}_{2}$ extraction of saponified anhydrous feedstock and by countercurrent column fractionation of esterified product, such as in the preliminary paper. In both cases squalene purities > $90 \%$ were achieved and also the feasibility of a contemporary squalene quantitative hydrogenation to squalane in supercritical fluid was demonstrated. More information about this project, concluded in 1999, can be found on the official site of European research www.cordis.lu, and a short note about the possibility to obtain squalene by $\mathrm{CO}_{2}$ fractionation was published by one of the partners (Brunner 2000). During all these investigations a weak point of the entire technology was individuated in squalene integrity. In other words the particular unsaturated structure of squalene can be damaged by chemical and thermal injury during refining (mainly during the

Table 2

Chemical properties of Olive Oil Deodoriser Distillates

\begin{tabular}{lcccccccc}
\hline & \multicolumn{8}{c}{ Sample } \\
\cline { 2 - 9 } Parameter & A & B & C & D & E & F & G & H \\
\hline $\begin{array}{l}\text { Squalene } \\
(\% \mathrm{~m} / \mathrm{m})\end{array}$ & 45.2 & 34.2 & 32.2 & 35.5 & 20.5 & 30.0 & 39.7 & 22.4 \\
$\begin{array}{l}\text { Saponification Value } \\
(\mathrm{mg} \mathrm{KOH} / \mathrm{g})\end{array}$ & 107.6 & 128.9 & 123.5 & 119.0 & 145.5 & 128.0 & 120.5 & 143.4 \\
$\begin{array}{l}\text { Acid Value } \\
(\mathrm{mg} \mathrm{KOH} / \mathrm{g})\end{array}$ & 58.1 & 63.2 & 86.0 & 81.0 & 113.8 & 93.8 & 80.6 & 110.2 \\
\hline
\end{tabular}


contact with $\mathrm{ABE}$ during bleaching) and during the esterification step preliminary to $\mathrm{CO}_{2}$ fractionation, as demonstrated by Bondioli et al. (1993) in the above mentioned paper. Two very interesting papers concerning the chemical identity of hydrocarbon fraction of olive oil and the changes observed during refining were published by Spanish researchers (Lanzon et al., 1994; Guinda et al., 1996).

One of the main problems encountered during the squalene project was the impressive distribution of feedstock for squalene recovery, and the poor availability of different manufacturers to keep OODD separated from the other by-products. This is a typical case where after solving the scientific/technical problems the project did not reach the industrial stage because of logistic/organisative problems. Starting from these published experiences and also using original technologies (not declared in detail by manufacturers) some European companies put on the market squalene of vegetable origin, in a wide range of quality and concentration. In parallel some Authors faced the problem of assessing the real vegetable origin of these samples, in consideration that the vegetable squalene has higher production costs and the possibility to sell animal squalene as vegetable still exist. Gasparoli et al. (1996) and Cecchi (1998) solved this problem by analysing the sterol fraction and the neoformed stearadienes respectively and detecting cholesterol and cholesterol derivatives in case of presence of animal squalene.

\section{CONCLUSIONS}

As a conclusion of our discussion on olive oil refining by-products we can summarise several key points:

- the management of refining by-products must be regarded with more attention than in the past, because they might represent a cost (in terms of yield losses and costs for disposal), but they may represent an economical support if efficiently valorised;

- under the technological and economical standpoint the best way for the management of by-products is avoiding to generate them. The actually available technologies and procedures for the handling and the transformation of the olive fruits in oil allow great improvements for the quality and the yield of the finished product;

- the olive oil refining by-products have some intrinsic potential, but for a more remunerative valorisation they must maintain their "certificate of origin", where the original source can be demonstrated and valorised. Once lost the plus of origin the by-product becomes commodity and the only possible competition is represented by the selling price;

- last but not least, when evaluating the possibility of an economical use of by-products, also the logistic problems and the transportation costs must be carefully evaluated, because of the strong impact of these items on the final success of the initiative.

\section{REFERENCES}

Agarwal A. K., Das L. M. 2001. Biodiesel development and characterisation for use as a fuel in compression and characterisation for use as a fuel in compression Turbines and Power 123 (2), 440-447.

Anonymous 2004. The world market of olive oil. Olivae 102, 14-16.

Bondioli P., Lanzani A., Foschi F. 1989. Bleaching of olive and residue oils in presence of amorphous synthetic silica. Paper presented at the Chevreul International congress on Oils and Fats, Angers (FR), 6-9 June 1989.

Bondioli P., Lanzani A., Fedeli E., Foschi F. 1990. Bleaching tests on vegetable oils using synthetic Bleaching tests on vegetable oils usin
silica. Riv. It. Sostanze Grasse 67, 75-79.

Bondioli P., Lanzani A., Fedeli E., Mossa A., Muller A. Isolation and purification of Squalene from Olive OI residues. European Patent no. 0541999 A1 (1.10.1992).

Bondioli P., Folegatti L., Lanzani A., Fedeli E., Savoini G. Dell'Orto V. 1993a. Fatty acid calcium soaps in anima feeding. In vitro behaviour and technological/practical considerations. Riv It Sostanze Grasse 70 (6), 271274 .

Bondioli P., Mariani C., Lanzani A., Fedeli E., Muller A 1993b. Squalene recovery from Olive Oil deodorise distillates. J. Am. Oil Chem. Soc. 70 (8), 763-766.

Bondioli P. 2001. Lubricants and hydraulic fluids in F. D. Gunstone and R. J. Hamilton (Ed.) "Oleochemical manufacture and applications". Sheffield Academic Press, Sheffield - UK.

Bondioli P., Sala M. 2005. The lubricants in use in food industry (It.). Riv. It. Sostanze Grasse 82 (3), 142-146

Brunner G. 2000. Fractionation of fats with supercritical carbon dioxide. Eur. J. Lipid Sci. Technol. 102, 240-244.

Casanova T. T. Preparation of Squalane. GB Patent no. 2 217729 A (1.11.1989)

Cecchi G. 1998. Sterol transformation during the production of vegetable squalene: impact of processing on the presence of stearanes in squalen from olive oil ( $F r$ r) $\mathrm{OCL}$ - Oleagineux, Corps Gras et Lipides 5 (2), 149-156.

CEE 1991. Regulation no. 2561/91 and further modifications.

Fedeli E., Jacini G. 1971. Lipid composition of vegetable oils in R. Paoletti and D. Kritchewsky (ed.) Advances in Lipid Research 9, 335-382. Academic Press New York, USA.

Gapor A., Kawada T., Watanabe H. Murjui T. 1985. Studies on minor components in palm fatty acid distillate. I. Occurrence of squalene. Yukagaku 34 (7), 551-553.

Gasparoli A., Mariani C., Fedrigucci M. G. (1996). Squalane: analytical differences between vegetable or animal source (It.). Riv. It. Sostanze Grasse 73, 293302

Guinda A., Lanzon A., Albi T. 1996. Differences in hydrocarbons of Virgin Olive Oils obtained from severa olive varieties. J. Agric. Food Chem. 44, 1723-1726.

Kalligeros S., Zannikos F., Stonmas S., Lois E. Anastoupolos G., Teas C., Sakallaropoulos F. 2003. An investigation of using biodiesel/marine diesel 
blends on the performance of a stationary diese engine. Biomass and Bioenergy 24, 141-149.

Lanzon A., Albi T., Cert A., Gracian J. 1994. The hydrocarbon fraction of Virgin Olive Oil and changes resulting from refining. J. Am. Oil Chem. Soc. 71 (3), 285-291.

Lavas B. 2003. From dumping to pumping. Oils \& Fats International 19 (4), 24-25.

Martinenghi G.B. 1971. Physical refining of oils and fats. Corbella Editore, Milano - IT.

Patterson H. B. W. 1992. Oil recovery in Bleaching and Purifying Fats and Oils. Theory and Practice. AOCS
Patterson H. B. Waching and Purifying Fats and Oils. Theory and Practice. AOCS
Press, Champaign, IL - USA. Press, Champaign, IL - USA.

production. INFORM 15 (11), 698-700. production. INFORM 15 (11), 698-700.

Sala M., Berardi S., Bondioli P. 1998. Amaranth seed: the potentialities (It.). Riv. It. Sostanze Grasse 75 (11), 503-506

Serra Maslé A., Martinez Moreno J M. 1981. Recovery of squalene from olive oil residues from physical refining (Sp.). Grasas y Aceites 32 (5), 313-317.

Sun H., Wiesenborn, D., Tostenson K., Gillespie J., Rayas-Duarte P. 1997. Fractionation of squalene from amaranth seed oil. J. Am. Oil Chem. Soc. 74 (4), 413418.

The Merck Index 1996, 20 $0^{\text {th }}$ Edition, edited by $\mathrm{S}$. Rudavari, Merck and Co. Inc., Whitehouse Station, New York - USA.

Recibido: Septiembre 2005 Aceptado: Noviembre 2005 